\title{
Zur sprachlichen Darstellung wiederholter vergangener Sachverhalte in der hebräischen Bibel
}

\author{
Krüger, Thomas
}

\begin{abstract}
Die diskutierten Textbeispiele legen die Annahme nahe, dass der Gebrauch der Verbformen WYQTL und QTL zur Darstellung wiederholter vergangener Sachverhalte nicht regelwidrig ist, sofern es aufgrund syntaktischer (Verbformen YQTL und WQTL) und lexikalischer Hinweise im Kontext hinreichend klar ist, dass nicht von einem einmaligen, sondern von einem wiederholten Geschehen die Rede ist. Für die Darstellung wiederholter vergangener Sachverhalte wird allem Anschein nach in erster Linie YQTL und WQTL verwendet, deren Hauptverwendung nicht vergangenheitsbezogen ist. Kombiniert damit können auch QTL und WYQTL gebraucht werden, deren Hauptverwendung vergangenheitsbezogen, aber nicht imperfektiv (und mithin auch nicht iterativ) ist. Beide Verbformen-Paare werden für die Darstellung wiederholter vergangener Sachverhalte sozusagen zweckentfremdet, weil für solche Sachverhalte keine eigenen Verbformen zur Verfügung stehen. Ihr Verständnis ist aber im jeweiligen Kontext, verbunden mit zusätzlichen lexikalischen Signalen, in der Regel unproblematisch. Bei der Übersetzung ins Deutsche lässt sich die formale Differenz zwischen YQTL / WQTL und QTL / WYQTL in Darstellungen wiederholter vergangener Sachverhalte meist nicht (oder jedenfalls nicht vollständig) abbilden.
\end{abstract}

Posted at the Zurich Open Repository and Archive, University of Zurich

ZORA URL: https://doi.org/10.5167/uzh-169338

Book Section

Published Version

Originally published at:

Krüger, Thomas (2019). Zur sprachlichen Darstellung wiederholter vergangener Sachverhalte in der hebräischen Bibel. In: Grätz, Sebastian; Graupner, Axel; Lanckau, Jörg. Ein Freund des Wortes: Festschrift Udo Rüterswörden. Göttingen: Vandenhoeck Ruprecht, 168-178. 
Thomas Krüger

\section{Zur sprachlichen Darstellung wiederholter vergan- gener Sachverhalte in der hebräischen Bibel}

Zur sprachlichen Darstellung wiederholter vergangener Sachverhalte stehen in der hebräischen Bibel zum einen die Verbformen YQTL und WQTL zur Verfügung, ${ }^{1}$ zum anderen Ausdrücke wie ,jährlich“"

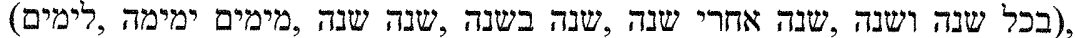

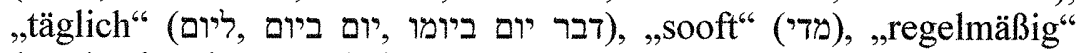

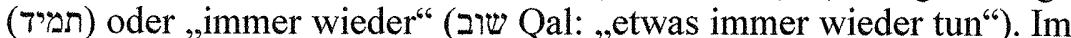
Folgenden sollen einige Beispiele für die Darstellung wiederholter vergangener Sachverhalte kurz diskutiert werden, wobei v.a. solche Texte betrachtet werden sollen, die Ausnahmen oder Unregelmäßigkeiten im Blick auf die Verbformen aufzuweisen scheinen. Zunächst jedoch zwei unkomplizierte Beispiele:

\section{Gen 29,2ff}

2 וירא * והנה באר בשדה * והנה שם שלשה עדרי צאן רבצים עליה * כי מן הבאר

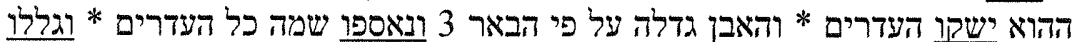
את האבן מעל פי הבאר * והשקו את הצאן * והשיבו את האבן על פי הבאר למקמה 4 ויאמר להם יעקב * ...

2 Und er schaute sich um, und sieh, da war ein Brunnen auf dem Feld. Und sieh, drei Schafherden lagerten daneben,

denn aus jenem Brunnen pflegte man die Herden zu tränken. Der Stein über der Öffnung des Brunnens aber war groß. 3 Wenn alle Herden dort zusammengetrieben waren, wälzte man den Stein von der Öffnung des Brunnens und tränkte die Schafe. Dann schob man den Stein wieder zurück über die Öffnung des Brunnens an seinen Platz. 4 Jakob sagte zu ihnen: ... ( $\left.\mathrm{ZHB}^{2}\right)$

1 Siehe z B. J. Joosten, The Verbal System of Biblical Hebrew, Jerusalem Biblical Studies 10, Jerusalem 2012, $285 \mathrm{ff}$. 305ff; J. JoOSTEN, ,The Verbal System of Biblical Hebrew ${ }^{66}$, Encyclopedia of Hebrew Language and Linguistics 3, 2013, 921-925: 923; R. BARTELMUS, $H Y H$ : Bedeutung und Funktion eines hebräischen „Allerweltswortes", ATS 17, St. Ottilien 1982, 59f. 76; R. BARTELMUS, Einführung in das Biblische Hebräisch, Zürich 1994, 204f; P. JOÜON/T. MURAOKA, A Grammar of Biblical Hebrew, Subsidia Biblica 27, Roma 2006, §113e. \$119v. $10)$

Die WYQTL-Verben ויאמר un in V.2 und V. 4 verbinden den Ausschnitt mit dem narrativen Kontext, in dem es um ein einmaliges vergangenes Geschehen geht. Jakob kam zu einem Brunnen in der Nähe von Charan. V. 2d und V. 3 insgesamt erzählen, wie man an diesem Brunnen täglich die Schafe zu tränken pflegte. Der Text verwendet dafür die Verbformen YQTL (ישקו) und WQTL (יגללו - ונאספו - והשיבו - והשקו Die Zürcher Bibel bringt die Iterativität des Sachverhalts im Deutschen durch die Ausdrücke ,pflegte ... zu ..." und „wenn ..." zum Ausdruck.

Ex 33,7ff

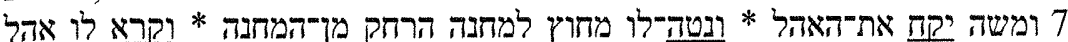

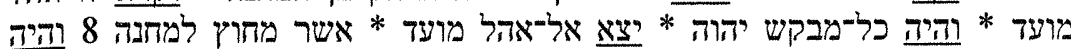

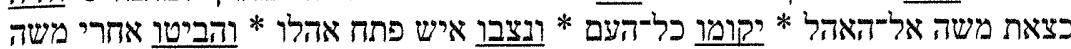

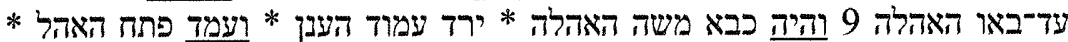

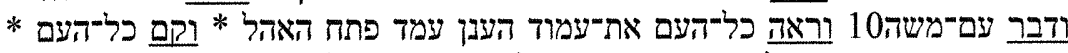

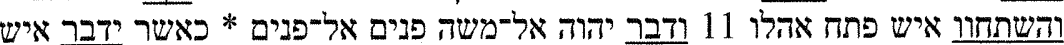

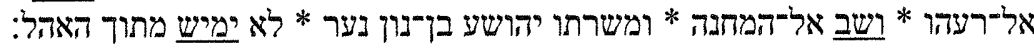

7 Mose aber nahm jeweils das Zelt und schlug es außerhalb des Lagers auf, in einiger Entfernung vom Lager, und er nannte es Zelt der Begegnung. Und jeder, der den HERRN befragen wollte, ging hinaus zum Zelt der Begegnung, das außerhalb des Lagers war. 8 Wenn nun Mose zum Zelt hinausging, erhob sich das ganze Volk, und jeder stellte sich an den Eingang seines Zelts, und sie schauten Mose nach, bis er in das Zelt hineingegangen war. 9 Und wenn Mose in das Zelt hineinging, kam die Wolkensäule herab und blieb am Eingang des Zelts stehen; und er redete mit Mose. 10 Und wenn dann das ganze Volk die Wolkensäule am Eingang des Zelts stehen sah, erhob sich das ganze Volk, und sie warfen sich nieder, jeder am Eingang seines Zelts. 11 Der HERR aber redete mit Mose von Angesicht zu Angesicht, wie ein Mensch mit einem anderen redet. Darauf kehrte er jeweils in das Lager zurück. Sein Diener Josua aber, der Sohn Nuns, ein junger Mann, entfernte sich nie aus dem Zelt. ${ }^{3}$ (ZHB)

Dies ist ein schönes Beispiel für eine längere Erzählung über einen wiederholten Vorgang in der Vergangenheit. Der Text benutzt durchgängig die Verbformen YQTL und WQTL. Die Zürcher Bibel bringt die Wiederholung im Deutschen durch, ,jeweils" und, ,wenn" zum Ausdruck. Ein wenig seltsam wirkt allenfalls V. 7c. Hat Mose dem Zelt wirklich jedes Mal, wenn er es aufgestellt hat, den Namen

${ }^{3}$ Folgt man der von mir im hebräischen Text vorgenommenen Satzabgrenzung (so auch W. RICHTER (Hg.), Biblia Hebraica transcripta, ATS 33.1-16, St Ottilien 1991-1993), wäre genauer zu übersetzen: „Sein Diener Josua aber, der Sohn Nuns, war ein junger Mann. Er entfernte sich nie aus dem Zelt.“ 
„Zelt der Begegnung“ gegeben? Oder ist „nennen“ hier nicht im Sinne einer einmaligen Namengebung zu verstehen, sondern in dem Sinne, dass Mose, wenn er von dem Zelt sprach, jeweils die Bezeichnung "Zelt der Begegnung" verwendete? Möglich wäre es schließlich auch, dass hier ein eigentlich einmaliger Sachverhalt durch Unachtsamkeit in die Darstellung einer Reihe von wiederholten Sachverhalten hineingeraten ist.

Jer 36,23

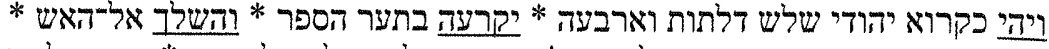

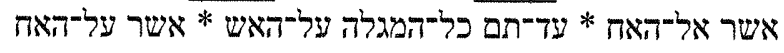

Und immer wenn Jehudi drei oder vier Spalten vorgelesen hatte, zerschnitt er [der König Jehojakim] sie [die Schriftrolle] mit dem Schreibermesser und warf sie in das Feuer, das im Kohlenbecken brannte, bis die ganze Rolle im Feuer vernichtet war, das im Kohlenbecken brannte. (ZHB)

Dieses kurze Beispiel ist deshalb interessant, weil hier ein wiederholter vergangener Vorgang (Verbformen YQTL und WQTL) wie die Darstellung eines einmaligen Geschehens eingeleitet wird. Die Zürcher Bibel korrigiert das stillschweigend, indem sie ... ויהי כקרוא übersetzt mit „und immer wenn Jehudi ... vorgelesen hatte“. Müsste man das WYQTL-Verb nicht eigentlich als Darstellung eines einmaligen Vorgangs verstehen: „und als Jehudi ... vorgelesen hatte"? Das würde aber nicht gut zum Folgenden passen. Zeigt dieser Text also, dass auch die Verbform WYQTL zur Darstellung von wiederholten vergangenen Sachverhalten gebraucht werden kann? Oder liegt hier ein nicht regelkonformer Sprachgebrauch vor - sei es, dass er bereits auf den oder die Verfasser des Textes zurückgeht oder auf ein Versehen in der späteren Textüberlieferung?

Eine Reihe von weiteren Belegen für WYQTL- und QTL-Verben, die sich auf wiederholte vergangene Sachverhalte beziehen (ohne Anspruch auf Vollständigkeit!) legt es m.E. nahe, dass dieser Sprachgebrauch nicht gegen die Regeln des Sprachsystems verstößt.

1. Sam $2,12 \mathrm{ff}$

12 ובני עלי בני בליעל * לא ידעו את־יהוה 13 ומשפט הכהנים את־העם * כל־־יש

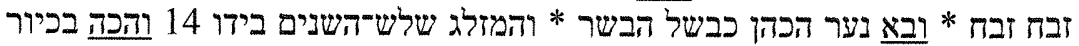

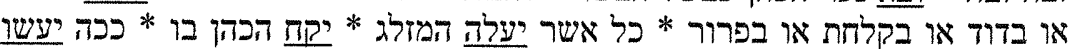

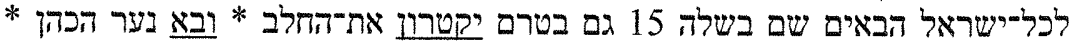

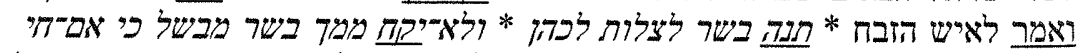

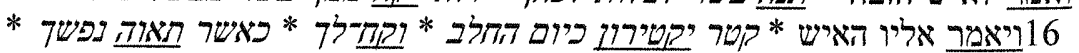

ואמר לו * כי עתה תתו * ואם-לא לקחתי בחזוקה 17 ותהי חטאת הנערים גדולה מאד את־פני יהוה * כי נתהצו האנשים את מנחת לתחת יהחוה

12 Die Söhne Elis aber waren ruchlos, sie kannten den HERRN nicht 13 und nicht das Recht der Priester beim Volk.

Immer wenn einer ein Schlachtopfer darbrachte, kam der Bursche des Priesters, wenn man das Fleisch kochte, und hatte eine Gabel mit drei Zinken in der Hand. 14 Und die stieß er dann in das Becken oder den Topf oder den Kessel oder die Pfanne. Alles, was die Gabel herausholte, nahm der Priester mit ihr. So machten sie es mit ganz Israel, mit denen, die dorthin kamen, nach Schilo. 15 Der Bursche des Priesters kam sogar, bevor man das Fett in Rauch aufgehen ließ, und sagte jeweils zu dem, der opferte: Gib Fleisch her, damit man es für den Priester braten kann; er nimmt von dir das Fleisch nicht gekocht, sondern wenn es roh ist. 16 Sagte der Mann dann aber zu ihm: Zuerst muss man das Fett verbrennen, dann nimm dir, was du willst!, so sagte er: Nein, gib es jetzt her, und wenn nicht, nehme ich es mit Gewalt.

17 Und die Sünde der jungen Männer war sehr groß vor dem HERRN, weil die Männer das Opfer für den HERRN verachteten. (ZHB)

Das rückblickend mit den Verbformen QTL und WYQTL formulierte Urteil über die Söhne Elis in V. 12 und V. 17 wird in V. 13-16 substantiiert mit einer Darstellung ihres wiederholten gewohnheitsmäßigen Verhaltens. Dabei verwenden V. 13-16 die Verbformen YQTL und WQTL, nur in V. 16 steht (abgesehen von den wörtlichen Reden) einmal WYQTL (ויאמר), allem Anschein nach ohne einen funktionalen Unterschied zum folgenden WQTL (ואמר).

1. Sam $27,8 \mathrm{ff}$

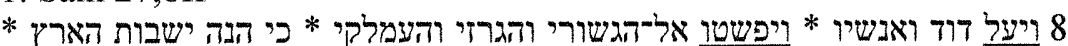

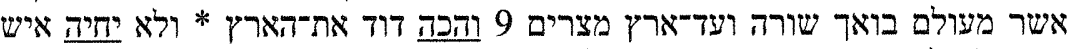

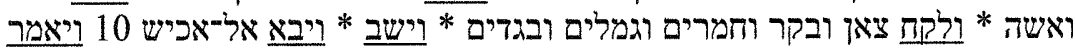

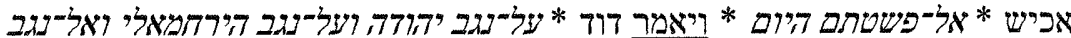

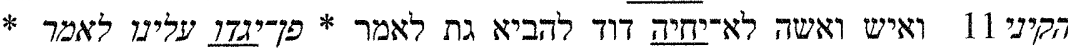

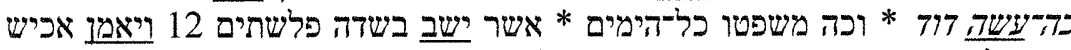
בדוד לאמר * הבאש הבאיש בעמו בישראל * והיה לי לעבד עולם פלשים

8 Und David zog mit seinen Männern hinauf, und sie fielen über die Geschuriter, die Gisriter und die Amalekiter her, denn das waren von alters her die Bewohner des Landes, das sich bis dort erstreckt, wo es nach Schur geht, und bis zum Land Ägypten.

9 Und wenn David das Land schlug, ließ er weder Mann noch Frau am Leben, und er nahm jeweils Schafe, Rinder, Esel, Kamele und Kleider; dann kehrte er zurück und ging zu Achisch. 10 Sagte Achisch dann: Wo seid ihr heute eingefallen?, so sagte David: In den Süden von Juda! In den Süden der Jerachmeeliten! In den Süden der Keniten! 11 David 
aber ließ weder Männer noch Frauen am Leben, die er hätte nach Gat bringen können. Er dachte: Dass sie nur nicht über uns berichten: So ist David verfahren!

Und so hielt er es, solange er auf dem offenen Land bei den Philistern wohnte. 12 Achisch aber schenkte David Glauben; er dachte: Er hat sich verhasst gemacht bei seinem Volk, bei Israel, und wird für immer mein Diener bleiben. (ZHB)

Die Überfälle Davids und seiner Männer auf die Geschuriter, Gisriter und Amalekiter werden in V.8 mit WAYYIQTOL-Verben (ויעל ויפשטו summarisch als ein Sachverhalt dargestellt. V.9ff erzählt detaillierter, wie David dabei in einer Reihe von Raubzügen jeweils nach gleichem Muster verfahren ist. In V. 9a-c und V. $11 \mathrm{a}-\mathrm{b}$ werden dabei die Verbformen YQTL und WQTL verwendet, in V.9d-10 dagegen die Verbform WYQTL. Auch hier muss es sich aber um wiederholte Sachverhalte handeln, wie nicht nur die Fortsetzung in V. 11 zeigt, sondern schon die verschiedenen Antworten Davids in V. 10d erkennen lassen. Auch hier bezieht sich also augenscheinlich WYQTL auf wiederholte vergangene Sachverhalte. In V. 11d-e Nominalsatz und QTL ישב) dürften dagegen wieder die gesamten zuvor berichteten Vorgänge als ein vergangener Sachverhalt im Blick sein, dessen Auswirkung V. 12 dann mit WYQTL (ויאמן) beschreibt.

\section{Sam $15,1 \mathrm{ff}$}

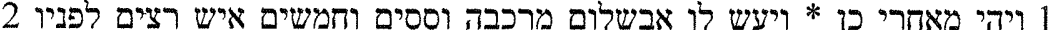

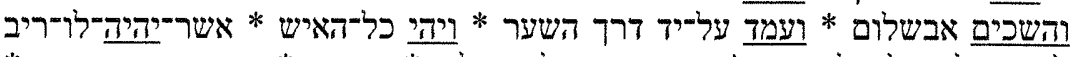

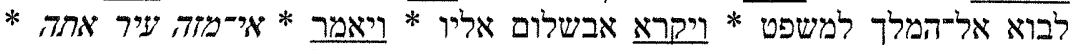

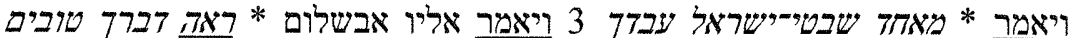

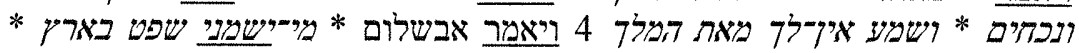

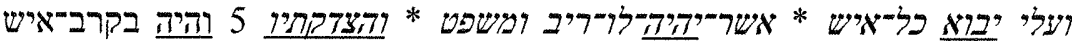

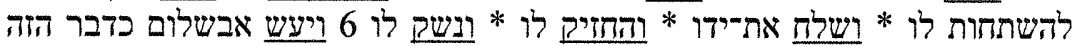
לכל־ישראל * אשר־־יבאו למשפט אל־המלך * ויגנב אבשלום את־לב אנשי ישראל כדבר

1 Und danach verschaffe sich Absalom einen Wagen, Pferde und fünfzig Mann, die vor ihm her liefen.

2 Und jeweils in der Frühe stellte Absalom sich neben den Torweg; dann rief Absalom jedem zu, der einen Streit hatte und zur Rechtsprechung zum König kam, und er sagte: Aus welcher Stadt bist du? Und sagte der: Dein Diener ist aus einem der Stämme Israels!, 3 so sagte Absalom zu ihm: Sieh, deine Sache ist gut und recht, aber du hast beim König niemanden, der dich anhört. 4 Dann sagte Absalom: Würde man doch mich einsetzen als Richter im Land! Dann könnte jeder zu mir kommen, der einen Rechtsstreit oder eine Rechtssache hat, und ich würde ihm Gerechtigkeit widerfahren lassen. 5 Und wenn jemand sich ihm näherte, um sich vor ihm niederzuwerfen, streckte er seine Hand aus, hielt ihn fest und küsste ihn.

6 Und das machte Absalom mit ganz Israel, wenn sie zur Rechtsprechung zum König kamen, und so stahl Absalom das Herz der Männer Israels. (ZHB)

Nach der narrativen Einleitung mit WYQTL in V. 1 (ויעש - ויהי) wird in V. 2 ff erzählt, was Absalom in Jerusalem zu tun pflegte. Dabei wird in V. 2 zuerst zweimal die Verbform WQTL verwendet (והשכים

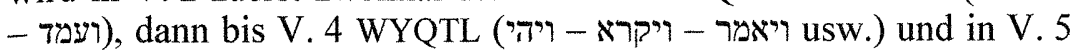
wieder WQTL (ונשק - והחזיק - ושלח - וניה - והיה). Ein Bedeutungsunterschied zwischen WQTL und WYQTL ist hier nicht zu erkennen. Hingegen könnte V. 6 (2x WYQTL: ויגנב - ויעש) als narrative Zusammenfassung verstanden werden, die auf den in V. 2-5 dargestellten wiederholten Sachverhalt (vgl. YQTL באו' in V 6b) als ganzen zurück-

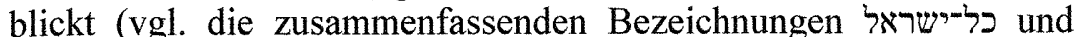
אנשי ישראל in V. 6 gegenüber אל־האיש in V. 2 und V. 5, die den Blick eher auf jeden einzelnen Fall lenken). Allerdings könnte man V. 6 auch iterativ verstehen (wofür der jedenfalls so zu interpretierende Satz V. 6b mit YQTL ביאו' sprechen könnte). Wie dem auch sei, V. 2c-4a sind jedenfalls ein weiteres Beispiel für einen Gebrauch der Verbform WYQTL zur Darstellung wiederholter vergangener Sachverhalte.

\section{Ri 6,2ff}

2 ותעז יד־מדין על-ישראל * מפני מדין עשו להם בני ישראל את־המנהרות * אשר

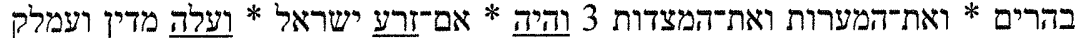

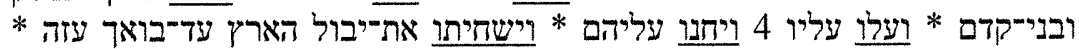

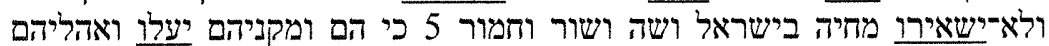

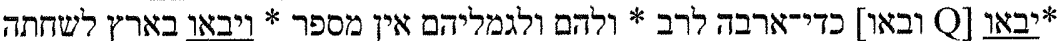

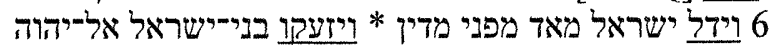

2 Und die Hand Midians war stark gegen Israel. Zum Schutz vor den Midianitern hatten sich die Israeliten die Schlupflöcher gemacht, die in den Bergen sind, und die Höhlen und Zufluchtsorte.

3 Und wenn Israel gesät hatte, zogen Midian und Amalek und die aus dem Osten herauf. Und sie zogen herauf gegen sie, 4 belagerten sie und vernichteten den Ertrag des Landes bis dorthin, wo man nach Gaza kommt, und sie ließen in Israel nichts zum Leben übrig, auch kein Schaf, kein Rind und keinen Esel. 5 Wenn sie mit ihren Herden und Zelten heranzogen, kamen sie so zahlreich wie Heuschrecken. Sie und ihre Kamele waren zahllos, und sie kamen ins Land, um es zu verwüsten.

6 So wurde Israel durch Midian sehr geschwächt, und die Israeliten schrien zum HERRN. (ZHB) 
Im Rahmen eines größeren Erzählzusammenhangs, zu dem V. 2 und V. 6 gehören (formuliert mit WYQTL und QTL), erzählen V. 3-5 von wiederholten Raubzügen der Midianiter und Amalekiter gegen Israel. Dabei werden in V. 3 Verben der Form WQTL verwendet (sowie einmal QTL, wobei die Iterativität durch das vorangestellte „,wenn“ klargestellt ist), in V. 4a-b Verben der Form WYQTL, und in V. 4c$5 b$ Verben der Form YQTL (folgt man dem Qere: YQTL und WQTL), ohne dass zwischen diesen Formen ein Bedeutungsunterschied zu erkennen wäre. (Bei V. 5d [ויבאו] ist nicht klar, ob dieser Satz noch zur Darstellung der wiederholten Angriffe gehört oder schon zu deren Resümee in V. 6.)

Hi 1,1ff:

1 איש היה בארץ־עוץ * איוב שמו * והיה האיש ההוא תם וישר וירא אלהים וסר

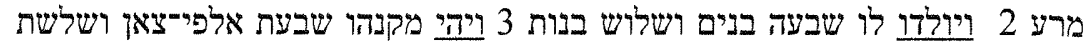

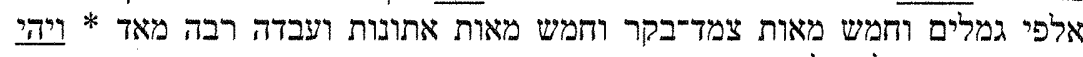

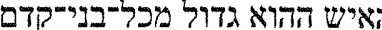
4 והלכו בניו * ועשו משתה בית איש יומו * ושלחו * וקראו לשלשת אחיתיהם

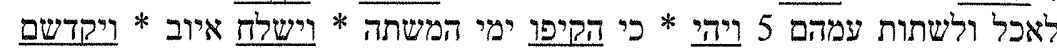
*והשכים בבקר * והעלה עלות מספר כלם * כי אמר איוב * אולי חטאו בני * וברכו אלהים בלבבם * ככה יעשה איוב כל־הימים מלים

6 ויהי היום * ויבאו בני האלהים להתיצב על־־ייהוה * ויבוא גם־השטן בתוכם ...

1 Im Lande Uz lebte ein Mann, der hieß Hiob.

Und dieser Mann war schuldlos und aufrecht, er fürchtete Gott und mied das Böse.

2 Und es wurden ihm sieben Söhne und drei Töchter geboren, 3 und er besaß siebentausend Schafe und dreitausend Kamele, fünfhundert Joch Rinder und fünfhundert Eselinnen und viel Gesinde. So war dieser Mann größer als alle anderen, die im Osten wohnten.

4 Seine Söhne aber pflegten Gastmähler zu halten, ein jeder in seinem Haus an seinem Tag. Und sie sandten zu ihren drei Schwestern und luden sie ein, mit ihnen zu essen und zu trinken. 5 Wenn dann die Tage des Gastmahls vorüber waren, sandte Hiob zu ihnen und ließ sie weihen, und früh am Morgen brachte er für jedes Kind ein Brandopfer dar. Denn Hiob dachte: Vielleicht haben meine Kinder gesündigt und Gott gelästert in ihrem Herzen. Das tat Hiob jedes Mal.

6 Eines Tages aber kamen die Götter, um vor den HERRN zu treten, und auch der Satan kam mit ihnen ... (ZHB)

Der Beginn der Erzählung situiert sie mit היה (QTL) in der Vergangenheit und führt ihren Hauptakteur Hiob ein. Mit והיה (WQTL) in V. 1c wird er durch sein habituelles (beständiges, immer wieder unter Beweis gestelltes) Verhalten charakterisiert. V. 2-3 erzählen zusammenfassend von Hiobs Nachkommen, seinem Vermögen (das
Menschen und Tiere umfasst) und seinem Ansehen (WYQTL: יולדו und 2x ויהי). In V. 4-5 folgt eine kurze Darstellung der immer wieder stattfindenden Feste der Kinder Hiobs und seiner Reaktion darauf. Sie wird mit Verben der Formen WQTL und YQTL formuliert (נוהלכו -

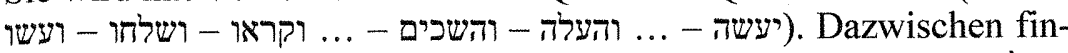

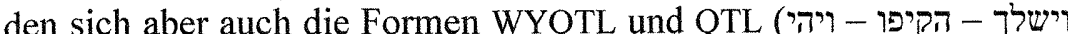
- אמר - ... ויקדשם - ohne dass damit ein erkennbarer Bedeutungsunterschied verbunden wäre. Ab V. 6 wird dann wieder ein einmaliges Geschehen erzählt (WYQTL: ויבאו - ויהי - ויהי).

1. Sam $1,1 \mathrm{ff}$

1 ויהי איש אחד מן־הרמתים צופים מהר אפרים * ושמו אלקנה בן־ירחם בן־אליהוא בן־תחו בן־צוף * אפרתי 2 ולו שתי נשים * שם אחת חנה * * ושם השנית פננה * ויהי לפננה ילדים * ולחנה איוף אירת ילדים

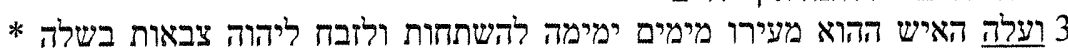

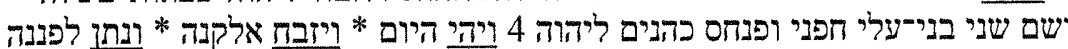

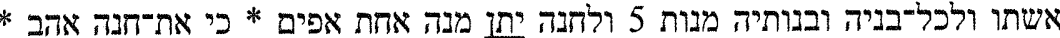

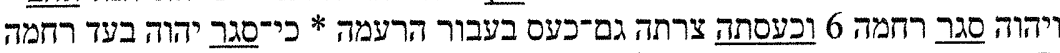

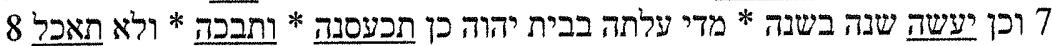

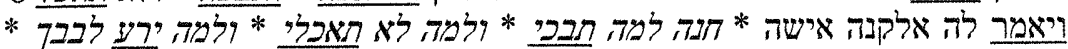
הלוא אנכי טוב לד מעשרה בעיה בנים

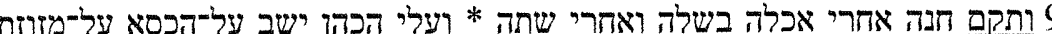

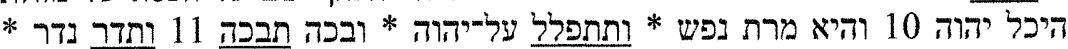

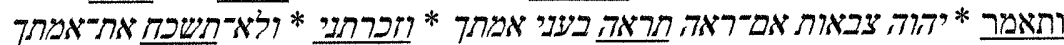

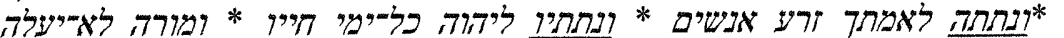

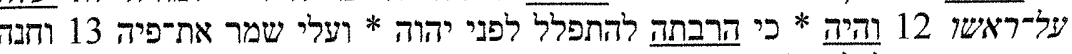

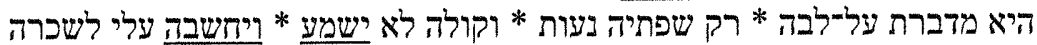
14 ויאמר אליה עלי * עד־מתי תשתכרין * הסירי את־ייפך מעליך *...

1 Und es war ein Mann aus Ramatajim-Zofim vom Gebirge Efraim, sein Name war Elkana, der Sohn Jerochams, des Sohns des Elihu, des Sohns des Tochu, des Sohns von Zuf, ein Efratiter. 2 Und der hatte zwei Frauen. Der Name der einen war Hanna, und der Name der zweiten war Peninna. Und Peninna hatte Kinder, Hanna aber hatte keine Kinder.

3 Und Jahr um Jahr zog dieser Mann aus seiner Stadt hinauf, um sich in Schilo niederzuwerfen und dem HERRN der Heerscharen zu opfern. Und die beiden Söhne Elis, Chofni und Pinechas, waren dort als Priester des HERRN 4 Und an dem Tag, an dem Elkana opferte, pflegte er Peninna, seiner Frau, und allen ihren Söhnen und Töchtern Anteile zu geben, 5 Hanna aber gab er jeweils einen doppelten Anteil, denn Hanna liebte er, der HERR aber hatte ihren Mutterleib verschlossen. 6 Und die andere Frau, die Hanna feind war, kränkte sie dann auch noch, um sie zu erniedrigen, weil der HERR ihren Mutterleib verschlossen hatte. 7 Und so war es Jahr für Jahr: Jedes Mal, wenn sie zum Haus des HERRN hinaufzog, kränkte jene sie in dieser Weise. Dann weinte sie und aß nichts. 8 Und 
Elkana, ihr Mann, sagte zu ihr: Hanna, warum weinst du, und warum isst du nicht, und warum ist dein Herz betrübt? Bin ich dir nicht wichtiger als zehn Söhne? 9 Und Hanna machte sich auf, nachdem man in Schilo gegessen und nachdem man getrunken hatte. Und Eli, der Priester, saß auf dem Stuhl am Türpfosten des Tempels des HERRN. 10 Sie aber war verbittert und betete zum HERRN und weinte heftig. 11 Und sie legte ein Gelübde ab und sprach: HERR der Heerscharen, wenn du das Elend deiner Magd siehst und an mich denkst, wenn du deine Magd nicht vergisst und deiner Magd männliche Nachkommenschaft gibst, will ich ihn dem HERRN geben, solange er lebt, und an sein Haupt soll kein Schermesser kommen. 12 Und als sie lange vor dem HERRN gebetet und Eli auf ihren Mund geachtet hatte, 13 - Hanna redete nämlich in ihrem Herzen, nur ihre Lippen bewegten sich, ihre Stimme aber war nicht zu hören - hielt Eli sie für betrunken. 14 Und Eli sagte zu ihr: ... (ZHB)

Ähnlich wie in Hi 1 wird auch hier nach der Einführung der Hauptakteure in V. 1-2 ab V. 3 mit WQTL und YQTL ein (jährlich) wiederholter Ereignisablauf erzählt. (Bei den drei Sätzen $5 b, 5 c$ und $6 b$ mit QTL-Verben handelt es sich um Rückblenden, die Sachverhalte beschreiben, deren Folgen während der wiederholten Vorgänge andauerten: Eli hatte Channa liebgewonnen und liebte sie seitdem; Jahwe hatte Channas Mutterleib verschlossen, weshalb sie unfruchtbar war.) Mit V. 7c wechseln die Verbformen zu WYQTL. (In V. 7d ist YQTL volitiv zu interpretieren: Channa ,wollte nicht essen“", in V. $10 \mathrm{c}$ im Sinne eines andauernden Begleitumstands zum vorhergehenden ותתפל , ,und dabei weinte sie heftig“, und in V. 13c modal: ,ihre Stimme konnte nicht gehört werden / war nicht zu hören“.) Auffällig sind in diesem Rahmen zum einen die beiden WYQTLVerben in V. 4a-b, zum anderen das WQTL והיה in V. 12a. Außerdem ist nicht ganz deutlich, ab wann nicht mehr von einem wiederholten Geschehen die Rede ist, sondern von einmaligen Ereignissen, die zur Geburt Samuels führen.

Jan Joosten hat vorgeschlagen, V. 4a-b als Beginn der Erzählung eines einmaligen Vorgangs zu verstehen:

is not something that happened every year, but a single event happening, one day'. I therefore take v. $4 \mathrm{a}$ as the beginning of the narrative, a kind of ,false start': having begun to recount what happened on the precise day when Hannah prayed for a child, the narrator is then reminded, as it were, that he hasn't yet provided all the necessary background - and launches into another series of frequentatives. If this analysis is acceptable, then we should probably suppose that the false start ${ }^{6}$ is a calculated step in the narrative strategy of the author: he introduces a break in the long exposition, in order not to loose the attention of his audience." $" 4$

Man kann allerdings fragen, ob der Autor seine Leserschaft mit einem solchen "Fehlstart" nicht mehr verwirren als bei der Stange halten würde. Eine einfachere Erklärung bietet Jan Joosten für die WYQTL-Form in V. 7c an:

"The best explanation of the wayyiqtol form in v. 7 is to say that although it is not marked for frequentativity-it merely expresses that the action occurred in the past - it does relate an action that took place habitually; its frequentative meaning derives entirely from the context."

Unabhängig davon, ob dieses Verständnis von V.7 zutrifft (s.u.), lässt es sich jedenfalls zwanglos auf die WYQTL-Verben in V.4 anwenden, die dann schlicht und einfach iterativ zu interpretieren wären. ${ }^{6}$

Schwieriger ist die Erklärung von והיה in V.12a. Soll die Verbform WQTL hier in Erinnerung rufen, dass (immer noch) von einem wiederholten Geschehen in der Vergangenheit die Rede ist? („Und immer, wenn sie viel gebetet hatte ... hielt Eli sie für betrunken ...6") Dann müsste man annehmen, dass sich auch das folgende Gespräch zwischen Eli und Channa (bis V. 18) jedes Jahr so abspielte. Spätestens in V. 20 (Channa war schwanger) ist aber nicht mehr von einem jährlich wiederholten Geschehen die Rede. Wo genau dieses endet und und nur noch von dem einen Jahr vor Samuels Geburt die Rede ist, sagt der Text nicht deutlich. Liegt der Übergang in V. 7c (ותבכה)? Aber hat Channa nur dieses eine Mal geweint? Liegt er in V. 8

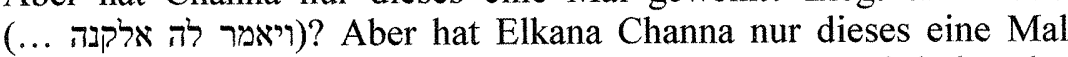
getröstet? V. 9 legt sich noch am ehesten nahe. Dann wird aber das WQTL והיה in V. 12a unverständlich - es sei denn, man nimmt mit Jan Joosten an, dass es sich hier nicht um die Verbform WQTL han-

4 J. Joosten, "Workshop: Meaning and Use of the Tenses in 1 Samuel 1", in: Ellen van Wolde $(\mathrm{Hg})$, Narrative Syntax and the Hebrew Bible, Biblical Interpretation Series 29, Leiden 1997, 72-83: 73

5 Joosten, „Tenses“, 73. Vgl. ebd. 80: „In v. 7, ותבכה continues the description of what used to happen every year. Only the context can tell that wayyiqtol signals the beginning of the main line of action in v. 4 and 8 , but continues the exposition in v. $7 .$.

6 ויהי היום bedeutet dann nicht „eines Tages“ - wörtlich: „und dann kam der Tag (an dem folgendes geschah)" (vgl. JoÜON/MURAOKA, Grammar, \$137n4) -, sondern „immer wieder" (,,und immer wieder kam der Tag ..."). Etwas freier kann man dann übersetzen: „Und immer wenn Elkana opferte, gab er ..." 
delt, sondern um eine „homonyme“ (bzw. homographe) Form w+QTL (vgl. WYQTL und $\mathrm{w}^{+}$YQTL). ${ }^{?}$

Hat der Verfasser den Übergang von dem alljährlich wiederholten zum einmaligen Geschehen absichtlich im Unklaren gelassen? (Aber welche Absicht sollte dahinterstehen?) Oder hat er das Problem schlicht übersehen? Resultiert die Unklarheit vielleicht aus einem mehrstufigen literarischen Wachstum des Textes? ${ }^{8}$

\section{Fazit}

Die diskutierten Textbeispiele legen die Annahme nahe, dass der Gebrauch der Verbformen WYQTL und QTL zur Darstellung wiederholter vergangener Sachverhalte nicht regelwidrig ist, sofern es aufgrund syntaktischer (Verbformen YQTL und WQTL) und lexikalischer Hinweise im Kontext hinreichend klar ist, dass nicht von einem einmaligen, sondern von einem wiederholten Geschehen die Rede ist. $^{9}$

Für die Darstellung wiederholter vergangener Sachverhalte wird allem Anschein nach in erster Linie YQTL und WQTL verwendet, deren Hauptverwendung nicht vergangenheitsbezogen ist. Kombiniert damit können auch QTL und WYQTL gebraucht werden, deren Hauptverwendung vergangenheitsbezogen, aber nicht imperfektiv (und mithin auch nicht iterativ) ist. Beide Verbformen-Paare werden für die Darstellung wiederholter vergangener Sachverhalte sozusagen zweckentfremdet, weil für solche Sachverhalte keine eigenen Verbformen zur Verfügung stehen. Ihr Verständnis ist aber im jeweiligen Kontext, verbunden mit zusätzlichen lexikalischen Signalen, in der Regel unproblematisch. Bei der Übersetzung ins Deutsche lässt sich die formale Differenz zwischen YQTL / WQTL und QTL / WYQTL in Darstellungen wiederholter vergangener Sachverhalte meist nicht (oder jedenfalls nicht vollständig) abbilden.

7 Joosten, „Tenses“, 74. „The solution is not elegant, because it postulates a case of grammatical ,homonymity"... but it is linguistically feasible" (ebd.). Vgl. ausführlicher JoOSTEN, System, 223ff. Von den ebd. 227f aufgezählten Belegen für W+QTL betreffen folgende das Verb היה: Gen 38,5; Ex 36,29.30;1. Sam 1,12;10,9; 17,$48 ; 25,20 ; 2$. Sam 6,$16 ; 1$. Kön 18,$4 ; 2$. Kön 3,15; Jer 3,9;37,11; 38,28; 40,3; Am 7,2; 1. Chr 9,26. (BHK schlägt noch vor, in 1. Sam 1,12 ויה zutatt lesen.)

8 Durch Herausschneiden von (V.3b und) V. 4c-8e ließe sich textchirurgisch recht einfach eine syntaktisch und narratologisch problemlose Erzählung herstellen. Wohlgemerkt ist aber auch der vorliegende Text syntaktisch nicht „falsch", sondern nur in seiner narrativen Organisation ein wenig unklar.

9 Vgl. Joosten, System, $174 \mathrm{f}$. 


\section{Ein Freund des Wortes}

Festschrift Udo Rüterswörden

Vandenhoeck \& Ruprecht 
Bibliografische Information der Deutschen Nationalbibliothek: Die Deutsche Nationalbibliothek verzeichnet diese Publikation in der Deutschen Nation im Internet über http://dnb.d-nb.de abrufbar.

C 2019, Vandenhoeck \& Ruprecht GmbH \& Co. KG, Theaterstraße 13, D-37073 Göttingen

Alle Rechte vorbehalten. Das Werk und seine Teile sind urheberrechtlich Alle Rechte vorbehalten. Das weren als den gesetzlich zugelassenen Fällen geschützt. Jede Verwertung in anderen als den gesetzlich zugelassenen

bedarf der vorherigen schriftlichen Einwilligung des Verlages.

Druck und Bindung: $\oplus$ Hubert \& Co BuchPartner, Göttingen Printed in the EU.

Vandenhoeck \& Ruprecht Verlage | www.vandenhoeck-ruprecht-verlage.com ISBN 978-3-525-57140-8 